\title{
Reescrita e escrita: investigando a visão do aluno
}

\author{
Rewriting and Writing: Investigating Student Vision \\ Rosemary da Silva Lima Oliveira* \\ Universidade do Estado da Bahia, Santo Antônio de Jesus, Bahia, Brasil \\ Valquíria Claudete Machado Borba** \\ Universidade do Estado da Babia, Santo Antônio de Jesus, Bahia, Brasil
}

\begin{abstract}
Resumo: Este artigo apresenta uma análise de uma investigação sobre reescrita e escrita, tendo em vista o olhar do aluno para a prática da reescrita na sala de aula. Como sujeitos, tivemos 30 alunos de $8^{\circ}$ ano do Ensino Fundamental de uma escola pública estadual de Santo Antônio de Jesus-BA. Utilizamos um questionário aberto, contendo 7 questões sobre o processo de reescrita. Os dados mostraram que a reescrita, conforme orientações e pesquisas atuais, não tem sido uma prática efetiva na sala de aula, uma vez que os dados mostraram que os alunos pouco compreendem o que é o processo de reescrita, fixando em aspectos superficiais do texto como questões gramaticais, ortográficas e de pontuação.
\end{abstract}

Palavras-chave: Reescrita. Escrita. Prática da reescrita.

\begin{abstract}
This article presents an analysis of an investigation about rewriting and writing, considering the student's perspective for the practice of rewriting in the classroom. Subjects were $308^{\text {th }}$ grade students of a public Elementary school located in Santo Antônio de Jesus, Bahia. An open questionnaire containing 7 questions about the rewriting process was used to collect data that showed that rewriting has not been an effective practice in the classroom. These results are aligned with guidelines and current research and showed that students do not understand what the rewriting process is and so they focus their attention on superficial aspects of the text such as grammar, spelling, and punctuation.
\end{abstract}

Keywords: Rewriting. Writing. Practice of rewriting.

\section{INTRODUÇÃO}

A escrita tem sido tema de debate didático entre os pesquisadores já há algum tempo, pois, apesar dos avanços teóricos, constitui-se ainda em um dos problemas educacionais em que os alunos têm apresentado maiores dificuldades.

A produção escrita dos alunos do Ensino Fundamental, especialmente de escolas públicas, tem sido motivo de preocupação para as ciências da educação e para professores desde as últimas décadas do século XX. Documentos oficiais como os Parâmetros Curriculares Nacionais (BRASIL, 1998), que estabelecem diretrizes curriculares para o ensino de Língua Portuguesa, encontros científicos (colóquios, jornadas de estudos, encontros), que defendem o texto enquanto objeto de estudo para entender os diversos fenômenos linguísticos, e resultados de

\footnotetext{
* Professora da Rede de Educação Estadual da Bahia, Santo Antônio de Jesus - BA, Brasil. Mestra em Letras pela Universidade do Estado da Bahia - UNEB.

** Professora do Departamento de Educação - Campus I e do Mestrado Profissional em Letras PROFLETRAS do Departamento de Ciências Humanas - Campus V da Universidade do Estado da Bahia - UNEB, Salvador, BA, Brasil. Email: valmborba@hotmail.com.
} 
trabalhos em sala de aula, que investigam as práticas de escrita e fazem progredir os estudos sobre a produção de textos escolares, muitos dos quais indicam a existência de um importante déficit de qualidade na escrita, são importantes movimentos na direção de se encontrar didáticas mais eficientes para o ensino da leitura e da escrita.

O desempenho insatisfatório contínuo de muitos alunos nesses campos tem sido tema de estudo do texto e seus usos na escola. Pesquisadores, como Bakhtin (2011), Marcuschi (2010), Dolz , Noverraz e Schneuwly (2004), dentre outros, ressaltam que existem variadas formas de linguagem, com características próprias, circulando em nossa sociedade, por isso, apontam para a relevância do contexto e da situação comunicativa nesses estudos. E passam a reconhecer a importância das situações de produção e de circulação dos textos, convocando a noção de gênero textual como sendo o mais apropriado suporte para desenvolvimento de estratégias e habilidades de leitura e produção oral e escrita no contexto escolar.

Contudo, diante dos atuais direcionamentos para o ensino de Língua Portuguesa, ensinar e aprender a produzir textos, orais ou escritos, não tem sido uma tarefa simples. Pensar sobre a produção textual é pensar sobre o aprendizado da língua materna, como ela tem acontecido nas escolas e, inevitavelmente, avaliar a eficiência do trabalho realizado na sala de aula.

Nessa direção, teorias e metodologias são constantemente produzidas nas universidades, mas muitos professores que atuam na base da educação nem sempre são alcançados por esses estudos, e enfrentam desafios e críticas severas de ordem teórico-metodológica à forma como assumem o texto no processo de ensinoaprendizagem, muitas vezes, focados em uma visão estática e reducionista da língua, enfatizando as sequências tipológicas (narração, descrição e dissertação) e utilizando o texto simplesmente como exemplar para o estudo de itens gramaticais, desconsiderando seu funcionamento e o contexto da sua produção.

Diante desse contexto, pensando no processo de escrita, buscamos aqui verificar como é vista uma das etapas da produção textual, a reescrita, a partir da visão do aluno. Conforme Gusmão (2015, p.19): “[...] ainda há muito a ser pesquisado sobre o ensino/aprendizagem da (re) escrita de textos no espaço da sala de aula [...] bem como as possibilidades de transformações que podem acontecer nesse contexto $[\ldots .$. ".

A partir do estudo de gêneros textuais, consideramos fundamental a etapa da reescrita nos processos de produção textual como forma de desenvolver a escrita. Por isso, buscamos verificar como essa etapa, a reescrita, tem sido compreendida e praticada a partir do olhar de alunos de $8^{\circ}$. ano do Ensino Fundamental, um passo inicial para estudos posteriores sobre a reescrita na sala de aula.

É necessário lançar um novo olhar sobre a escrita na escola, já que uma questão comumente associada às dificuldades de ensino-aprendizagem da Língua Portuguesa diz respeito às condições referentes ao processo de produção textual. Esse complexo processo da escrita envolve diversas etapas que se inter-relacionam: planejamento da escrita, efetivação do texto, revisão e reescrita. Entretanto, nem sempre essas etapas são levadas em consideração por alunos e professores, principalmente no tocante às atividades de reescrita. 


\section{REESCRITA: ETAPA FUNDAMENTAL NO PROCESSO DA ESCRITA}

Estudos de natureza cognitivista e textual procuram explicar os processos e as fases implicados na escrita. Kato (1995) compreende a escrita do ponto de vista de um processo composto por diversos níveis e etapas ligados recursivamente: planejamento, escritura e revisão (leitura e correção). Para a autora, o planejamento não ocorre somente antes da escrita, e esta em um outro momento anterior à revisão: cada fase pode estar atravessada por outras, de modo que, durante a revisão, por exemplo, o sujeito pode recorrer ao planejamento. O importante é que "A meta principal [...] do redator é conseguir que o texto faça sentido.” (KATO, 1995 p.97).

Ao escrever, o sujeito mobiliza e coordena um conjunto de conhecimentos e habilidades: conhecimento do sistema de escrita, do conteúdo a ser apresentado no texto, da organização textual, da situação enunciativa e dos tipos de enunciados adequados a essa situação. Desse modo, fica evidente a complexidade da produção de texto, e o aluno precisa lidar com os diversos fatores implicados nessa atividade. "Tarefa que nem sempre é fácil para um aprendiz da escrita" (LEITE, 2009, p 24).

Estudos linguísticos afirmam que a escrita é um processo complexo que envolve etapas inter-relacionadas: o planejamento, a escrita e a revisão/reescrita. A escrita é uma tarefa que abrange várias atividades e etapas a serem cumpridas, por isso, o aluno pode ter dificuldade de gerenciar com eficiência todos os fatores que se concentram nessa tarefa. Para Menegassi (1998, p. 75): “A escrita é um trabalho que se desenvolve em diversos processos que envolvem desde o plano das ideias até a versão final de um texto."

Nessa perspectiva, temos os modelos de processamento de escrita postulados por Serafini (1992), a qual se reveste de caráter mais didático. Essa autora propõe quatro etapas para a escrita: plano, produção de ideias, produção do texto e revisão. Já para Antunes (2003, p.54), existem três etapas para a escrita entendidas como "distintas e intercomplementares", quais sejam: etapa de planejamento, etapa da escrita e etapa da revisão e da reescrita; em que, cada qual cumpre uma função particular que, quando respeitadas, apresentam maiores chances de uma eficácia comunicativa. Ressaltamos que a etapa da revisão e da reescrita, a qual nos interessa, é o momento de analisar toda a estrutura textual (macro e micro), verificar a execução do objetivo, conferir o atendimento à temática, enfim é o momento de aprimorar o texto.

O termo reescrita encontra-se presente nos livros didáticos, em discussões sobre o ensino da escrita e em diretrizes curriculares. E, em virtude das propostas atuais de ensino de Língua Portuguesa, o espaço teoricamente concedido à atividade de reescrita textual tem sido maior. Conforme postula Fiad; Mayrink-Sabinson:

Sabe-se que, desde os anos 80 , no contexto brasileiro, a prática de análise linguística foi proposta, em documentos oficiais sobre o ensino de português, como uma atividade que permite a realização da reescrita no contexto escolar. Mesmo sabendo que as práticas escolares não são necessariamente uma resposta ao que os documentos propõem, pode-se supor que há algum diálogo entre os documentos 
oficiais e as práticas escolares de escrita. (FIAD; MAYRINK-SABINSON, 2015, p.08).

Contudo, sabemos que, no atual sistema de ensino, alguns docentes nem sempre conseguem ampliar as circunstâncias de produção textual, muito menos de exercer seu real papel de interlocutor do texto produzido pelo aluno. Os motivos são diversos: excessiva carga horária de trabalho semanal, classes numerosas, falta de tempo para corrigir a grande quantidade de textos, etc. Por isso, muitas vezes, a prática de produção escrita acontece na escola seguindo apenas roteiros como, por exemplo: leitura e interpretação de determinado gênero; produção escrita de um exemplar desse gênero; correção do texto, com algumas observações; devolução desse texto, que quando recebido, muitas vezes, é descartado pelo aluno, o qual se interessa apenas em verificar a nota atribuída à atividade. "Para o professor, vem a decepção de ver textos mal redigidos, aos quais ele havia feito sugestões, corrigido, tratado com carinho. No final, o aluno nem relê o texto com as anotações. Muitas vezes o atira ao cesto do lixo assim que o recebe." (GERALDI, 2011, p. 65). Sem dúvida, a sala de aula é um lugar bem complexo. Há muitos fatores (cognitivos, afetivos, internos, externos e materiais) que interferem na prática do professor, que exigem dele constante esforço e reflexão acerca de sua forma de trabalhar, para que consiga alcançar os objetivos de ensino-aprendizagem pretendidos.

Dessa forma, quando nos referimos ao ensino da produção escrita, nos deparamos com vários problemas. E, embora todas as etapas citadas sejam inerentes ao processo de produção textual, nem sempre o procedimento da reescrita é levado em consideração na sala de aula.

Ressaltamos que existe uma diversidade de nomenclatura: reescrita, refacção, retextualização, e adotaremos, nesse trabalho, o termo reescrita, considerando esta etapa como momento em que há reflexão e alterações realizadas pelo aluno no seu próprio texto, ou seja, uma escrita para outra, reescrevendo o mesmo texto. Em consonância com as palavras de Gusmão (2015, p. 106):

Consideramos a reescrita a atividade realizada pelo professor e aluno conjuntamente ou alunos e colegas em que parte da leitura da primeira versão do texto escrito para realizar um trabalho de reflexão interativa/dialógica sobre o discurso, aspectos internos e externos e a variedade padrão da língua e, consequentemente, a escrita de uma nova versão do texto. Essa ação implica, portanto, um trabalho de aperfeiçoamento do texto.

É importante, portanto, dizer que a reescrita se constitui como uma atitude reflexiva, na qual o aluno é capaz de retomar, olhar, refletir, se debruçar sobre seu texto, avaliar sua produção escrita, atuar sobre ela e promover mudanças necessárias, como forma melhorá-la.

Os PCN, ao abordarem a prática da produção textual, afirmam que: "[...] um texto pronto será quase sempre produto de sucessivas versões." (BRASIL, 1998, p.77). Em outras palavras, dificilmente uma produção textual será produzida sem passar por reformulações, revisões e reescritas.

Conforme os PCN, por meio da refacção textual, o professor pode desenvolver importantes atividades: 
Um dos aspectos fundamentais da prática de análise linguística é a refacção dos textos produzidos pelos alunos. Tomando como ponto de partida o texto produzido pelo aluno, o professor pode trabalhar tanto os aspectos relacionados às características estruturais dos diversos tipos textuais como também os aspectos gramaticais que possam instrumentalizar o aluno no domínio da modalidade escrita da língua. (BRASIL, 1998, p.80).

A reescrita é uma etapa fundamental do processo de produção textual, é uma importante atividade de reflexão acerca do próprio texto, é um momento de melhoramento da produção escrita, que visa deixá-la mais compreensível ao interlocutor, exercendo sua função comunicativa.

Vale ressaltar que a relevância sobre essa reescrita, aqui defendida, vai ao encontro do que afirma Menegolo; Menegolo (2005, p.75), ao esclarecer que:

Quanto mais o ato de reescrever acontecer, mais o autor irá perceber que todo texto poderá ser modificado, que não é um produto de dimensões significativas acabadas, e assim vai ganhando condições de domínio da modalidade escrita [...] melhorando seu desempenho redacional e compreendendo, ao poucos, o mundo dos textos escritos.

Ao tratarmos de práticas de reescrita, no ambiente de ensino-aprendizagem, estamos nos referindo também à etapa de revisão, pois entendemos que não é possível reescrever sem revisar e na atividade de revisão, pressupõe-se a intenção da reescrita. Conforme salienta Menegassi: “[...] revisão e reescrita são processos complementares, pois juntas auxiliam a melhor construção do texto. Por meio da revisão, o autor analisa seu produto, reflete a respeito dos elementos escolhidos, observando se suas escolhas colaboram para que seus objetivos sejam atingidos." (2013, p.111).

Nesse sentido, Antunes (2003, p.55, 56) afirma que:

A etapa da revisão e reescrita corresponde ao momento de análise do que foi escrito, para aquele que escreve confirmar se os objetivos foram cumpridos, se conseguiu a concentração temática desejada, se há coerência e clareza no desenvolvimento das ideias, se há encadeamento entre os vários segmentos do texto.

No Brasil, há importantes publicações que apresentam reflexões e pesquisas sobre as atividades de revisão e reescrita, sendo exemplos significativos: Grillo (1995), Menegassi (1998), Leite (2009), Nascimento (2009), Jesus (2011) e Gusmão (2015).

Grillo (1995) focalizou, em seu trabalho, a interação professor/ aluno em atividades de revisão ou reescrita de textos e observou que o sucesso das atividades de reescrita depende do modo de participação do professor e da habilidade do sujeito em realizar mudanças em seu texto. $\mathrm{O}$ estudo verificou que ao explicitar o problema e apresentar possíveis soluções, o professor provoca reformulações 
importantes, que contribuem para a melhora das produções dos alunos. Assim, a interação constituiu-se como um apoio para resolver os problemas. As instruções do professor foram essenciais para solucionar problemas de base textual, como a coesão, a coerência e a adequação ao gênero textual proposto.

Menegassi (1998), em sua pesquisa, analisou os processos de escrita e estudou as etapas de revisão e reescrita no processo de construção do texto de alunos, examinando também a influência dos comentários de sugestões de revisão feitos pelo professor nos textos dos alunos, concluindo que o modo como se dão esses comentários de revisão do professor no texto do aluno são fundamentais para a construção da reescrita.

Com base nesses estudos, acreditamos que a prática da revisão e da reescrita contribui para um melhor trabalho de construção textual. Essas etapas são tão importantes quanto as etapas de planejamento e execução. Por isso, é preciso que professor e aluno compreendam essas etapas como uma prática a ser constantemente desenvolvida.

Leite (2009), numa pesquisa com a turma de $9^{\circ}$ ano de uma escola pública, analisou os critérios abordados na correção do professor e na reescrita decorrentes da correção; os critérios que são mais enfatizados na correção do professor e a pertinência do trabalho implementado e sua implicação no texto final do aluno. Ressalta ainda a importância da correção feita pelos professores para estimular a reescrita dos alunos.

Já Nascimento (2009) propõe uma reflexão sobre os bilhetes escritos pelos professores nas correções de trabalhos dos alunos, analisando como esses bilhetes podem contribuir para a aprendizagem do gênero relatório de experiência, produzidos pelos alunos do $5^{\circ}$ ano do Ensino Fundamental.

Nesses dois últimos trabalhos, os pesquisadores partem do pressuposto de que a aprendizagem da escrita é um processo de mediação entre professor e aluno, e abordam como as formas de correção exercem influência no desenvolvimento de habilidade da escrita.

Em seu trabalho sobre a reescrita, Jesus (2011) observou que um dos problemas das atividades da reescrita desenvolvidas na escola é essa prática estar voltada apenas para a estrutura superficial do texto, os aspectos periféricos como problemas ortográficos ou de acentuação.

O trabalho de reescrita de texto caracterizava-se por aquilo que podemos chamar de "higienização do texto do aluno". A reescrita transformava-se numa espécie de "operação limpeza", em que o objetivo principal consistia em eliminar as 'impurezas' previstas pela profilaxia linguística, ou seja, os textos são analisados apenas ao nível da transgressão ao estabelecido pelas regras de ortografia, concordância e pontuação, sem se dar a devida importância às relações de sentido emergentes na interlocução (JESUS, 2011, p.104).

Para a autora, uma revisão preocupada apenas com as normas gramaticais irá proporcionar "uma reescrita formal e mecânica, destituída de significado e reflexão" (JESUS, 2011, p. 111). 
De acordo com Grillo (1995), a realização dessa revisão voltada somente para os desvios gramaticais ocorre porque, dentre outros fatores, "a formação da maioria dos professores de português ainda é fortemente baseada nos estudos da gramática normativa, mas muito deficiente em termos de estudos linguísticos". (GRILLO, 1995, p. 60).

Conforme já colocamos, há sim muitas práticas didáticas pautadas no ensino tradicionalista, nos dias atuais, entretanto acreditamos que esse cenário esteja mudando progressivamente. O que pode ser constatado na mais recente pesquisa de Gusmão (2015), que investiga as ações pedagógicas de uma professora durante práticas de (re) escrita de textos com crianças do $3^{\circ}$ ano do ensino fundamental, e apresenta importantes reflexões sobre as possibilidades e limites do trabalho com a (re) escrita de textos em sala de aula, assim como reflexões acerca da natureza interativa e dialógica da linguagem. Gusmão compreende que a professora, mesmo com receio, arriscou transformar sua prática e assumir um ensino mais produtivo, centrado na mediação. Assim, a autora considera que:

[...] as ações reflexivas pedagógicas no ensino/aprendizagem da (re) escrita de textos incluem inúmeras fases e sofre influência das reações mediadoras dialógicas, adquirindo movimentos de ruptura e continuidade na construção de uma nova práxis docente, mais consciente, crítica e autônoma. (GUSMÃO, 2015, p.198).

Portanto, fica claro que os estudiosos aqui apresentados compreendem que:

[...] é necessário refletir sobre o texto e revisá-lo para aprimorá-lo; [...] esse comportamento deve ser estimulado e ensinado, com o intuito de formar produtores de textos numa acepção mais ampla, que planejem, escrevam, revisem e, se preciso, reescrevam seus textos. (LEITE; PEREIRA, 2013, p. 62).

A reescrita é mais do que a reformulação de palavras, de parágrafos ou textos, é um procedimento que funciona como um movimento de idas e voltas, que evidencia seus interlocutores. É, pois, uma ressignificação que contribui para a aprendizagem do aluno, o que reflete na melhora da qualidade da escrita.

\section{A REESCRITA NA SALA DE AULA: O QUE DIZ O ALUNO?}

Tendo em vista nosso interesse neste estudo, buscamos identificar com que frequência os alunos escrevem na sala de aula, como veem a reescrita e como a praticam. Para isso, distribuímos o questionário abaixo, que propunha respostas discursivas e solicitamos que respondessem com atenção. Essa atividade, com duração de 2 (h/aula), aconteceu com trinta alunos do $8^{\circ}$ ano do Ensino Fundamental, matutino, de uma escola estadual do município de Santo Antonio de Jesus - Bahia. 
1) Com que frequência você escreve textos na escola? E para quais atividades?

2) Você revisa seus textos antes de entregar ao professor? Se sim, o que você costuma observar na revisão?

3) Quando o(a) professor (a) devolve seu texto corrigido, você analisa o que foi corrigido? Por quê?

4) Qual a diferença entre revisar e reescrever um texto?

5) $\mathrm{Na}$ escola, você tem atividades de reescrita? Como são?

6) Você costuma reescrever seu texto? Se sim, o que você faz para reescrevê-lo?

7) O que você acha da atividade de reescrita de um texto?

Organizamos os questionários dos alunos por ordem alfabética e numeramos. Utilizamos a letra A maiúscula, seguida do número corresponde à posição de acordo com a ordem alfabética, para representar cada aluno.

Quadro 1: Perguntas do questionário

\begin{tabular}{|c|c|c|c|c|c|c|c|c|c|c|c|c|c|c|c|c|}
\hline \multirow[b]{2}{*}{\begin{tabular}{l}
0 \\
0 \\
$z$ \\
3 \\
\multirow{4}{4}{}
\end{tabular}} & \multicolumn{16}{|c|}{ PERGUNTAS } \\
\hline & \multicolumn{2}{|c|}{ 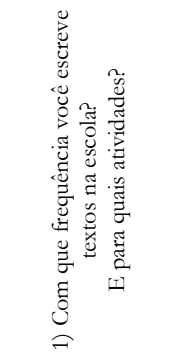 } & \multicolumn{3}{|c|}{ 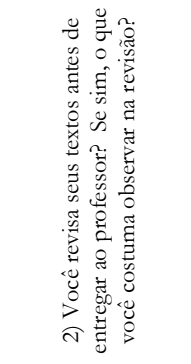 } & & \multicolumn{3}{|c|}{ 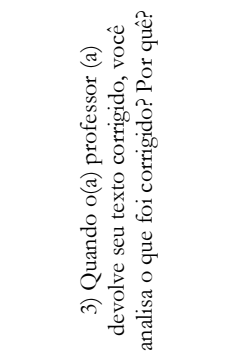 } & 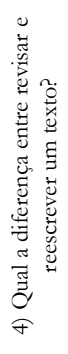 & \multicolumn{3}{|c|}{ 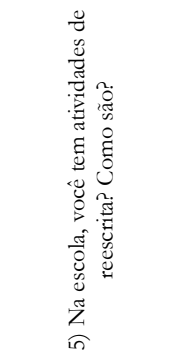 } & \multicolumn{2}{|c|}{ 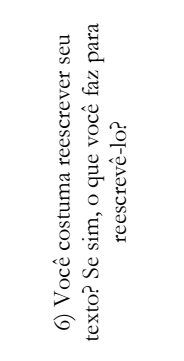 } & 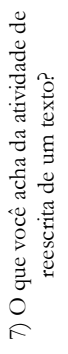 \\
\hline A1 & 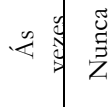 & 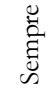 & & 安章 & & & 乎总 & 芯 & 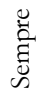 & & 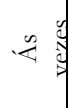 & & 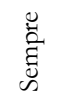 & 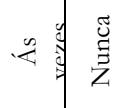 & 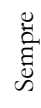 & \\
\hline
\end{tabular}

Em relação à primeira questão sobre a frequência com que o aluno escreve textos na escola e para quais atividades, obtivemos as seguintes respostas:

Quadro 2: Respostas da primeira questão do questionário

\begin{tabular}{|c|c|c|c|}
\hline ALUNOS & $\begin{array}{l}\text { 1) Com que frequência você escreve } \\
\text { textos na escola? E para quais } \\
\text { atividades? }\end{array}$ & ALUNOS & $\begin{array}{l}\text { 1) Com que frequência você escreve } \\
\text { textos na escola? E para quais } \\
\text { atividades? }\end{array}$ \\
\hline A1 & $\begin{array}{l}\text { Sempre. Escreve textos nas matérias: } \\
\text { História, Português e Ciências. }\end{array}$ & A16 & Sempre. Em resumos e atividades. \\
\hline A2 & $\begin{array}{l}\text { Sempre. Escreve textos nas matérias: } \\
\text { Geografia, Português, Ciências e } \\
\text { principalmente em História. }\end{array}$ & A17 & Sempre. Em atividades significativas. \\
\hline A3 & $\begin{array}{l}\text { Às vezes. Em: Geografia, Português, } \\
\text { Ciências e História. }\end{array}$ & A18 & $\begin{array}{l}\text { Sempre. Em: Geografia, Português, } \\
\text { Ciências e História, }\end{array}$ \\
\hline A4 & Sempre. & A19 & $\begin{array}{l}\text { Sempre. Em matérias como História } \\
\text { (resumos), Português. }\end{array}$ \\
\hline A5 & $\begin{array}{l}\begin{array}{l}\text { Sempre. Em } \\
\text { significativas. }\end{array} \\
\text { resumos e }\end{array}$ & A20 & Às vezes. Em História. \\
\hline A6 & $\begin{array}{l}\text { Sempre. Em matérias como História, } \\
\text { Ciências, Geografia e Português. }\end{array}$ & A21 & $\begin{array}{l}\text { Sempre. Em matérias como História, } \\
\text { Ciências, Geografia e Português. }\end{array}$ \\
\hline
\end{tabular}




\begin{tabular}{|c|c|c|c|}
\hline A7 & $\begin{array}{l}\text { Às vezes. Em matérias como História e } \\
\text { Português. }\end{array}$ & A22 & Às vezes. \\
\hline A8 & $\begin{array}{l}\text { Sempre. Em matérias como História } \\
\text { (resumos), Português e Ciências. }\end{array}$ & A23 & Sempre. Em todas as matérias. \\
\hline A9 & $\begin{array}{l}\text { Sempre. Em matérias como História e, às } \\
\text { vezes, em Ciências. }\end{array}$ & A24 & $\begin{array}{l}\text { Sempre. Em matérias como História } \\
\text { (resumos). }\end{array}$ \\
\hline A10 & $\begin{array}{l}\text { Às vezes. Em: Geografia, Português, } \\
\text { Ciências e História, }\end{array}$ & A25 & Às vezes. Na matéria História. \\
\hline A11 & Sempre. Em História e, às vezes, Ciências. & A26 & $\begin{array}{l}\text { Sempre. Em matérias como História, } \\
\text { Geografia e Português. }\end{array}$ \\
\hline A12 & $\begin{array}{l}\text { Sempre. Em matérias como História } \\
\text { (resumos), Português, Matemática e } \\
\text { Ciências. }\end{array}$ & A27 & $\begin{array}{l}\text { Sempre. Em matérias como História } \\
\text { (resumos), Português e Ciências. }\end{array}$ \\
\hline A13 & Sempre. Em História. & A28 & Sempre. \\
\hline A14 & "Faz e escreve com atenção." & A29 & $\begin{array}{l}\text { Às vezes. Em algumas matérias como } \\
\text { História e Ciências, Inglês, Geografia, } \\
\text { Artes e Português. }\end{array}$ \\
\hline A15 & $\begin{array}{l}\text { Sempre. Em matérias como História e } \\
\text { Ciências (resumos) e em Português. }\end{array}$ & A30 & $\begin{array}{l}\text { Sempre. Em todas as matérias. Em } \\
\text { História (resumos). }\end{array}$ \\
\hline
\end{tabular}

Podemos verificar que 23 alunos informam que as atividades de escrita acontecem frequentemente na escola e 07 dizem que, às vezes, acontecem essas atividades. É notório que, embora sejam alunos da mesma turma, esses últimos deram respostas diferentes. Provavelmente eles estejam julgando insuficiente a quantidade de vezes com que as atividades acontecem na escola; talvez estejam se referido à pouca frequência com que eles mesmos realizam essa ação; ou simplesmente estejam afirmando que a escrita não ocorre cotidianamente. Apesar da informação positiva nessa questão, a maioria não consegue responder que tipo de atividade escrita é solicitada; eles parecem confundir atividades de escrita com a disciplina que as solicita.

Outro ponto relevante nessa primeira questão foi o fato de alguns alunos informarem que na disciplina História, frequentemente fazem resumo. É importante chamar a atenção para isso. Conforme Schneuwly e Dolz (2004), o resumo escolar constitui-se num importante instrumento de ensino/aprendizagem, pois contribui para o trabalho de análise e de interpretação de textos. Entretanto, apesar de ser muito solicitado nas atividades escolares, muitas vezes, exigem que o aluno produza um texto que tenha as características principais e definidoras do resumo, sem criar estratégias adequadas para exploração/dominação deste gênero. Consequentemente, alegam que o aluno apresenta dificuldades em realizar o processo de resumir e que, quando o faz é de forma insuficiente, pois não seleciona o essencial e não consegue apresentar o conteúdo de forma concisa. Infelizmente, esse procedimento do professor acarreta deficiências no processo da leitura e da escrita dos alunos e, consequentemente no domínio do gênero textual. Assim, a atividade torna-se insignificante, quando realizada sem objetivos bem definidos.

$\mathrm{Na}$ segunda questão, sobre revisão dos textos, temos:

Quadro 3: Respostas da segunda questão do questionário.

\begin{tabular}{|c|c|c|c|}
\hline ALUNOS & $\begin{array}{l}\text { 2) Você revisa seus textos antes de } \\
\text { entregar ao professor? Se sim, o que } \\
\text { você costuma observar na revisão? }\end{array}$ & ALUNOS & $\begin{array}{l}\text { 2) Você revisa seus textos antes de } \\
\text { entregar ao professor? Se sim, o que } \\
\text { você costuma observar na revisão? }\end{array}$ \\
\hline A1 & Sim. O que a professora explica. & A16 & Às vezes. "Só quando dá tempo". \\
\hline A2 & Sim. Ortografia. & A17 & Sim. Os erros. \\
\hline
\end{tabular}


ISSN $1415-8973$

\begin{tabular}{|c|c|c|c|}
\hline A3 & Sim. As perguntas que escreveu. & A18 & $\begin{array}{l}\text { Sim. Observa aquilo que a professora } \\
\text { ensina. }\end{array}$ \\
\hline A4 & Sim. A escrita das palavras. & A19 & Não. \\
\hline A5 & $\begin{array}{l}\text { Sim. Erros ortográficos, separação de } \\
\text { sílabas, margens. }\end{array}$ & A20 & Não observa nada. \\
\hline A6 & Sim. Para verificar se não falta nada. & A21 & Sim. Erros ortográficos. \\
\hline A7 & Sim. Para ter certeza do que escreveu. & A22 & Sim. Os erros. \\
\hline A8 & Sim. Ortografia. & A23 & Sim. A letra e os erros. \\
\hline A9 & Não. & A24 & Sim. A escrita das palavras. \\
\hline A10 & Não. & A25 & Sim. A escrita das palavras. \\
\hline A11 & Não & A26 & Sim. Pontuação. \\
\hline A12 & Sim. Ortografia. & A27 & Sim. Corrige os erros. \\
\hline A13 & Não. & A28 & Sim. Aquilo que a professora indica. \\
\hline A14 & Sim. Verifica se tem questão errada. & A29 & Sim. Observa se o texto está certo ou não. \\
\hline A15 & $\begin{array}{l}\text { Sim. Ortografia e se o texto está dentro do } \\
\text { assunto. }\end{array}$ & A30 & Às vezes. A escrita das palavras. \\
\hline
\end{tabular}

A partir das respostas, 22 alunos afirmaram que revisam o texto antes de entregar, desses, a maioria verifica os desvios gramaticais (pontuação, ortografia, acentuação), 02 corrigem aquilo que a professora explica/indica e 01 aluno costuma observar os erros gramaticais e se o texto está "dentro do assunto". 05 alunos informam que não revisam o texto, 03 informaram que revisam às vezes e 01 aluno afirma que não observa nada. O que podemos depreender dessas afirmações? $\mathrm{Na}$ etapa da revisão, a maioria se volta somente para os aspectos da superfície do texto, as correções gramaticais, não demonstrando preocupação em constatar problemas como a clareza e a organização do texto, com o desenvolvimento das ideias ou com a adequação ao gênero exigido. Nesse sentido, supomos que, embora os alunos demonstrem interesse em realizar a etapa de revisão, não têm conhecimento do importante papel que esse processo desenvolve na construção do texto e provavelmente não dominam a estratégia da revisão.

$\mathrm{Na}$ terceira questão, perguntamos sobre a forma como recepcionam e analisam os textos corrigidos pelo professor. Vejamos as respostas:

Quadro 4: Respostas da terceira questão do questionário

\begin{tabular}{|l|l|}
\hline ALUNOS & $\begin{array}{l}\text { 3) Quando o(a) professor (a) devolve } \\
\text { seu texto corrigido, você analisa o que } \\
\text { foi corrigido? Por quê? }\end{array}$ \\
\hline A1 & Sim. Analisa os erros e a nota. \\
\hline A2 & Sim. Para não cometer os mesmos erros. \\
\hline A3 & Sim. Porque gosta e ler suas histórias. \\
\hline A4 & Sim. Analisa os erros e a nota. \\
\hline A5 & $\begin{array}{l}\text { Sim. Corrige os erros para melhorar no } \\
\text { próximo texto }\end{array}$ \\
\hline A6 & Sim. Analisa somente as notas. \\
\hline A7 & Sim. Para consertar os erros. \\
\hline A8 & Sim. Para não cometer os mesmos erros. \\
\hline A9 & Não. Analisa somente as notas. \\
\hline
\end{tabular}

\begin{tabular}{|l|l|} 
ALUNOS & $\begin{array}{l}\text { 3) Quando o(a) professor (a) devolve } \\
\text { seu texto corrigido, você analisa o que } \\
\text { foi corrigido? Por quê? }\end{array}$ \\
\hline A16 & $\begin{array}{l}\text { Sim. Verifica os erros para não cometê-los } \\
\text { novamente. }\end{array}$ \\
\hline A17 & Sim. Para não cometer os mesmos erros. \\
\hline A18 & Sim. Analisa o texto. \\
\hline A19 & Sim. Analisa os erros e a nota. \\
\hline A20 & Sim. Analisa os erros para evitar repetição. \\
\hline A21 & Sim. Ajuda a aprender com o erro. \\
\hline A22 & Sim. "Porque é importante." \\
\hline A23 & \\
\hline A24 & Não. Analisa somente a nota. \\
\hline
\end{tabular}




\begin{tabular}{|c|c|c|c|}
\hline A10 & Sim. Para não cometer os mesmos erros. & A25 & Sim. Verifica se a professora corrigiu certo. \\
\hline A11 & Não. Oberva somente as notas. & A26 & Sim. "Para melhorar da próxima vez". \\
\hline A12 & $\begin{array}{l}\text { Sim. Verifica os erros para não cometê-los } \\
\text { novamente. }\end{array}$ & A27 & Sim. Analisa os erros. \\
\hline A13 & Sim. Verifica os erros. & A28 & $\begin{array}{l}\text { Sim. Verifica os erros para não cometê-los } \\
\text { novamente. }\end{array}$ \\
\hline$\overline{\mathrm{A} 14}$ & Sim. Analisa os erros. & A29 & Às vezes. "O importante é a nota". \\
\hline A15 & Sim. Analisa os erros e a nota. & A30 & $\begin{array}{l}\text { Sim. Analisa os erros na atividade de } \\
\text { Matemática. }\end{array}$ \\
\hline
\end{tabular}

Nesta questão, a maioria afirmou que analisa o que a professora corrige em seus textos, verificando os erros para evitar repeti-los nas próximas atividades; 04 afirmaram se interessar somente pela nota. Apenas 04 alunos disseram não analisar o texto corrigido, mas, desses, 03 afirmaram se interessar pela nota. 01 não atendeu ao enunciado da questão. Essas respostas nos revelam que muitos alunos valorizam a correção do professor. Porém, nos aparece que o tratamento dado à produção escrita do aluno indica somente a correção de questões gramaticais: acentuação, grafia e pontuação, desconsiderando outros aspectos importantes para a construção do texto, como por exemplo, a adequação ao gênero textual, a coesão e a coerência, ou seja, as questões linguístico-discursivas mais significativas são deixadas às margens.

$\mathrm{Na}$ quarta questão, buscamos verificar o conhecimento dos alunos sobre os procedimentos da revisão e reescrita. E obtivemos os seguintes resultados:

Quadro 5: Respostas da quarta questão do questionário

\begin{tabular}{|c|c|c|c|}
\hline ALUNOS & $\begin{array}{l}\text { 4) Qual a diferença entre revisar e } \\
\text { reescrever um texto? }\end{array}$ & ALUNOS & $\begin{array}{l}\text { 4) Qual a diferença entre revisar } \mathrm{e} \\
\text { reescrever um texto? }\end{array}$ \\
\hline A1 & $\begin{array}{l}\text { Revisar: é só estudar. } \\
\text { Reescrever: escrever tudo de novo. }\end{array}$ & A16 & $\begin{array}{l}\text { Revisar: é fazer e responder } \\
\text { Reescrever: recopiar o que já está escrito. }\end{array}$ \\
\hline A2 & $\begin{array}{l}\text { Revisar: é corrigir o erro. } \\
\text { Reescrever: recopiar sem corrigir. }\end{array}$ & A17 & $\begin{array}{l}\text { Revisar: é verificar se está certo. } \\
\text { Reescrever: é copiar o texto e fazer } \\
\text { resumo da atividade. }\end{array}$ \\
\hline A3 & $\begin{array}{l}\text { Revisar: é corrigir o errado. } \\
\text { Reescrever: é copiar o mesmo texto. }\end{array}$ & A18 & $\begin{array}{l}\text { Revisar: é “olhar” o texto inteiro. } \\
\text { Reescrever: escrever de novo. }\end{array}$ \\
\hline A4 & $\begin{array}{l}\text { Revisar: verificar se está tudo certo. } \\
\text { Reescrever: escrever a mesma frase, } \\
\text { corretamente. }\end{array}$ & A19 & $\begin{array}{l}\text { Revisar: é ler o texto. } \\
\text { Reescrever: é escrever o mesmo texto. }\end{array}$ \\
\hline A5 & $\begin{array}{l}\text { Revisar: verificar se tem algo errado. } \\
\text { Reescrever: refazer o texto. }\end{array}$ & A20 & $\begin{array}{l}\text { Revisar: é corrigir. } \\
\text { Reescrever: passar a limpo. }\end{array}$ \\
\hline A6 & $\begin{array}{l}\text { Revisar: verificar se não falta nada. } \\
\text { Reescrever: repetir o texto que já foi } \\
\text { escrito. }\end{array}$ & A21 & $\begin{array}{l}\text { Revisar: verificar os erros. } \\
\text { Reescrever: corrigir os erros. }\end{array}$ \\
\hline A7 & $\begin{array}{l}\text { Revisar: fazer pela "nossa cabeça" } \\
\text { Reescrever: só escreve. }\end{array}$ & A22 & $\begin{array}{l}\text { Revisar: é encontrar os erros. } \\
\text { Reescrever: é passar a limpo. }\end{array}$ \\
\hline A8 & $\begin{array}{l}\text { Revisar: é verificar os erros. } \\
\text { Reescrever: é escrever a mesma coisa. }\end{array}$ & A23 & $\begin{array}{l}\text { Revisar: ver se tem algo errado. } \\
\text { Reescrever: é corrigir aquilo que errou. }\end{array}$ \\
\hline A9 & $\begin{array}{l}\text { Revisar: é verificar o erro. } \\
\text { Reescrever: é passar a limpo. }\end{array}$ & A24 & $\begin{array}{l}\text { Revisar: é ler o texto. } \\
\text { Reescrever: é escrever um texto. }\end{array}$ \\
\hline A10 & $\begin{array}{l}\text { Revisar: "olhar o texto" } \\
\text { Reescrever: é reescrever o texto antes de } \\
\text { entregar. }\end{array}$ & A25 & $\begin{array}{l}\text { Revisar: verificar se há erros. } \\
\text { Reescrever: é escrever o texto novamente. }\end{array}$ \\
\hline A11 & $\begin{array}{l}\text { Revisar: verificar os erros. } \\
\text { Reescrever: reescrever o texto. }\end{array}$ & A26 & $\begin{array}{l}\text { Revisar: é reler e gravar. } \\
\text { Reescrever: é passar a limpo. }\end{array}$ \\
\hline A12 & $\begin{array}{l}\text { Revisar: analisar os erros. } \\
\text { Reescrever: escrever tudo de novo, passar } \\
\text { a limpo. }\end{array}$ & A27 & $\begin{array}{l}\text { Revisar: verificar o que foi feito. } \\
\text { Reescrever: corrigir o erro e passar a } \\
\text { limpo. }\end{array}$ \\
\hline A13 & $\begin{array}{l}\text { Revisar: verificar os erros. } \\
\text { Reescrever: escrever o texto mais uma vez. }\end{array}$ & A28 & $\begin{array}{l}\text { Revisar: é verificar os erros. } \\
\text { Reescrever: é escrever novamente e passar } \\
\text { a limpo. }\end{array}$ \\
\hline
\end{tabular}




\begin{tabular}{|l|l|l|l|l|}
\hline $\mathbf{A} 14$ & $\begin{array}{l}\text { Revisar: é uma revisão. } \\
\text { Reescrever: é escrever. }\end{array}$ & \multirow{2}{A}{ A29 } & $\begin{array}{l}\text { Revisar: é passar a limpo e resumir. } \\
\text { Reescrever: é corrigir os erros e escrever } \\
\text { novamente. }\end{array}$ \\
\cline { 1 - 4 } $\mathbf{A 1 5}$ & $\begin{array}{l}\text { Revisar: verificar acertos e erros. } \\
\text { Reescrever: refazer o texto. }\end{array}$ & $\mathbf{A 3 0}$ & $\begin{array}{l}\text { Revisar: analisar aquilo que errou. } \\
\text { Reescrever: é escrever a mesma coisa. }\end{array}$ \\
\hline
\end{tabular}

Os alunos demonstraram que compreendem a etapa da revisão como uma atividade de verificação de erros gramaticais. Enquanto que a reescrita é considerada somente como uma atividade de corrigir esses erros gramaticais e "passar o texto a limpo", a qual consiste na preocupação somente com o nível superficial do texto: aspecto estético e correções localizadas de normas ortográficas. Ação que desconsidera os problemas que interferem na construção de sentido da produção textual.

Com relação à atividade de reescrita, questionada na quinta questão, tivemos:

Quadro 6: Respostas da quinta questão do questionário

\begin{tabular}{|c|c|c|c|}
\hline ALUNOS & $\begin{array}{l}\text { 5) Na escola, você tem atividades de } \\
\text { reescrita? Como são? }\end{array}$ & ALUNOS & $\begin{array}{l}\text { 5) Na escola, você tem atividades de } \\
\text { reescrita? Como são? }\end{array}$ \\
\hline A1 & Sim. Ruim e cansativa. & A16 & Sim. São boas, mas cansam. \\
\hline A2 & Não. Por falta de tempo. & A17 & $\begin{array}{l}\text { Às vezes. Os professores escrevem } \\
\text { demais. }\end{array}$ \\
\hline A3 & Não. & A18 & Sim. São muito legais. \\
\hline A4 & Não. & A19 & Sim. Mas não gosta. \\
\hline A5 & Não. & A20 & Sim. São legais e interessantes. \\
\hline A6 & Não. & A21 & Às vezes. \\
\hline A7 & Sim. Em cada unidade de Português. & A22 & Sim. Vários resumos \\
\hline A8 & $\begin{array}{l}\text { Sim. Quando a atividade está rasurada e a } \\
\text { professora determina. }\end{array}$ & A23 & Sim. São legais. \\
\hline A9 & Ás vezes. & A24 & Sim. \\
\hline A10 & Às vezes. & A25 & Não. \\
\hline A11 & Não. & A26 & Sim. Resumo. \\
\hline A12 & $\begin{array}{l}\text { Sim. Não se considera competente em } \\
\text { reescrita }\end{array}$ & A27 & $\begin{array}{l}\text { Às vezes. Quando a professora devolve o } \\
\text { texto, passa a limpo. }\end{array}$ \\
\hline A13 & $\begin{array}{l}\text { Não sabe responder, pois está sempre } \\
\text { ausente. }\end{array}$ & A28 & Sim. São atividades legais. \\
\hline A14 & Sim. Os resumos da disciplina História. & A29 & Sim. Corrige os erros. \\
\hline A15 & $\begin{array}{l}\text { Sim. "Fazer sem rasuras para melhorar a } \\
\text { nota". }\end{array}$ & A30 & $\begin{array}{l}\text { Sim. Quando está rasurado e a professora } \\
\text { indica. }\end{array}$ \\
\hline
\end{tabular}

Aqui, 17 alunos afirmaram que têm essa prática na escola, 05 disseram que somente às vezes e 09 informaram que não, variando muito sobre o que seriam essas atividades. Essas respostas revelam que não há um consenso sobre o que os alunos consideram atividades de reescrita e nem compreendem o que seria considerado durante uma atividade de reescrita.

Quando perguntados se costumam reescrever seus textos, na sexta questão, tivemos as seguintes respostas:

Quadro 7: Respostas da sexta questão do questionário

\begin{tabular}{|l|l|l|l|l|}
\hline ALUNOS & $\begin{array}{l}\text { 6) Você costuma reescrever seu texto? } \\
\text { Se sim, o que você faz para reescrevê- } \\
\text { lo? }\end{array}$ & ALUNOS & $\begin{array}{l}\text { 6) Você costuma reescrever seu texto? } \\
\text { Se sim, o que você faz para reescrevê- } \\
\text { lo? }\end{array}$ \\
\hline A1 & \begin{tabular}{l} 
Sim. Faz releitura de tudo que escreve. \\
\cline { 1 - 1 } A2
\end{tabular} & $\begin{array}{l}\text { Sim. Verifica os erros, a letra e a } \\
\text { organização. }\end{array}$ & A16 & Sim. Corrige ortografia e pontuação. \\
\hline A3 & $\begin{array}{l}\text { Sim. Gosta de copiar do livro e atividade } \\
\text { da escola }\end{array}$ & A18 & Sim. "Pensa e imagina". \\
\hline
\end{tabular}




\begin{tabular}{|c|c|c|c|}
\hline $\mathbf{A 4}$ & Às vezes. Somente quando está errado. & A19 & Não. \\
\hline$\overline{A 5}$ & Não. Só revisa. & $\mathbf{A 2 0}$ & Sim. Passa a limpo. \\
\hline A6 & Não. & A21 & $\begin{array}{l}\text { Sim. Obseva o que não está "bom" e } \\
\text { reescreve. }\end{array}$ \\
\hline A7 & Sim. Para corrigir os erros. & A22 & Não. Não acha importante. \\
\hline A8 & Às vezes. Quando tem erros. & A23 & Sim. Reescreve para aprender a escrever. \\
\hline A9 & Não. & A24 & Não. Considera "chata". \\
\hline A10 & Não. & A25 & Sim. Somente corrige os erros. \\
\hline A11 & Não. & A26 & Não. Não gosta. \\
\hline A12 & Sim. Sempre que a professora determina & A27 & $\begin{array}{l}\text { Sim. Faz a letra mais legível e corrige os } \\
\text { erros. }\end{array}$ \\
\hline A13 & Sim. Somente quando acha necessário. & A28 & $\begin{array}{l}\text { Sim. Verifica o texto "antigo" par ver os } \\
\text { erros e passa a limpo. }\end{array}$ \\
\hline A14 & Sim. "Escrevendo tudo novamente." & A29 & Às vezes. Apenas lê o texto. \\
\hline A15 & $\begin{array}{l}\text { Sim. Baseia-se no texto "antigo" para fazer } \\
\text { um novo. }\end{array}$ & A30 & Sim. Quando comete muitos erros. \\
\hline
\end{tabular}

Nesta questão, 18 alunos afirmam que sim, 03 disseram que às vezes e 09 afirmaram que não reescrevem. Embora a maioria afirme, nessas duas últimas questões, que realiza a atividade de rescrita, muitos alunos não conseguem informar como acontecem as atividades de reescrita na escola nem como fazem para reescrever seus textos. Poucos admitem que corrigem somente os erros gramaticais e que depois reescrevem o texto, e 02 alunos citaram a rasura como único motivo para a reescrita. Essas respostas nos revelam que as atividades de revisão e reescrita parecem não estar sendo consideradas nem por professores nem por alunos como parte integrante do processo da escrita, o que impede o entendimento por parte dos alunos da produção textual como um objeto que pode e deve ser retrabalhado, revisto, revisado e reescrito, levando em consideração não apenas aspectos de superfície, mas aspectos como coerência, coesão, contexto, etc.

No último questionamento, procuramos saber qual o ponto de vista dos alunos a respeito da atividade de reescrita.

Quadro 8: Respostas da sétima questão do questionário

\begin{tabular}{|c|c|c|c|}
\hline ALUNOS & $\begin{array}{l}\text { 7) } \mathrm{O} \text { que você acha da atividade } \\
\text { de reescrita de um texto? }\end{array}$ & ALUNOS & $\begin{array}{l}\text { 7) O que você acha da atividade de } \\
\text { reescrita de um texto? }\end{array}$ \\
\hline A1 & Considera ruim e muito cansativa. & A16 & $\begin{array}{l}\text { Às vezes considera uma atividade boa, outras } \\
\text { vezes acha ruim. }\end{array}$ \\
\hline A2 & $\begin{array}{l}\text { Considera uma atividade muito } \\
\text { cansativa. }\end{array}$ & A17 & Não gosta, mas acha uma atividade importante. \\
\hline A3 & $\begin{array}{l}\text { Muito bem. Considera uma atividade } \\
\text { para melhorar o texto. }\end{array}$ & A18 & Reescreve o texto. \\
\hline A4 & Considera muito legal. & A19 & Acha desnecessária. \\
\hline A5 & $\begin{array}{l}\text { Uma atividade que pode melhorar o } \\
\text { texto. }\end{array}$ & A20 & Considera legal e gosta muito. \\
\hline A6 & $\begin{array}{l}\text { Considera uma atividade que serve } \\
\text { para aprender a fazer texto. }\end{array}$ & A21 & $\begin{array}{l}\text { Considera bom, porque ajuda a mente a } \\
\text { "funcionar" melhor ajuda a aprender com os } \\
\text { erros. }\end{array}$ \\
\hline A7 & Considera muito chata. & $\mathbf{A 2 2}$ & Considera uma atividade pouco importante. \\
\hline A8 & $\begin{array}{l}\text { Às vezes considera uma atividade } \\
\text { interessante, outras vezes acha chata. }\end{array}$ & A23 & $\begin{array}{l}\text { Considera uma atividade legal, porque aprende } \\
\text { a escrever corretamente. }\end{array}$ \\
\hline A9 & Não gosta muito. & A24 & Não gosta. \\
\hline A10 & Considera legal e interessante. & A25 & É bom para aprender mais. \\
\hline A11 & Não gosta muito. & A26 & Não gosta da atividade. \\
\hline A12 & $\begin{array}{l}\text { Não gosta, mas considera uma } \\
\text { atividade importante. }\end{array}$ & A27 & $\begin{array}{l}\text { Considera uma atividade chata, mas } \\
\text { importante. }\end{array}$ \\
\hline A13 & $\begin{array}{l}\text { Atividade que permite verificar os } \\
\text { acertos e erros. }\end{array}$ & A28 & Considera uma atividade legal. \\
\hline
\end{tabular}




\begin{tabular}{|l|l|l|l|l|}
\hline A14 & Considera interessante. & \multirow{2}{*}{ A29 } & $\begin{array}{l}\text { Considera uma atividade boa para corrigir os } \\
\text { erros. }\end{array}$ \\
\cline { 1 - 2 } A15 & $\begin{array}{l}\text { Tem preguiça de reescrever texto, } \\
\text { principalmente se for extenso. }\end{array}$ & $\mathbf{A} 30$ & Às vezes considera muito chata. \\
\hline
\end{tabular}

Nesta questão, 08 alunos evidenciam que consideram atividade da reescrita "chata", ruim, pouco interessante, desnecessária e cansativa. Outros 05 afirmam que "não gostam" da atividade; 07 alunos consideram uma atividade que serve para aprender a "fazer" texto, para melhorar o texto ou para corrigir os erros; 06 alunos afirmam que a reescrita é uma atividade importante, mas não apresentam argumentos plausíveis que sustentem essa afirmação, pois se utilizam de palavras imprecisas e vagas como: legal, interessante e boa, para caracterizar a reescrita. Apenas 01 aluno afirma ter preguiça para reescrever seus textos e outro responde somente que reescreve, sem emitir opinião sobre a atividade.

\section{CONCLUSÃO}

Averiguamos neste estudo se a reescrita é uma prática usual no desenvolvimento da escrita através de um questionário, identificando com que frequência os alunos produzem textos na escola e como veem a reescrita. As informações obtidas sobre a atividade de reescrita na escola mostram que os alunos não têm uma visão clara do que seria de fato reescrever um texto, o que considerar, apresentando certa resistência à atividade de reescrita. Há ainda uma visão da reescrita muito forte de correção gramatical, ortográfica e de pontuação. Percebemos que os alunos não compreendem a reescrita como um momento de reflexão sobre o objetivo do texto, a estrutura geral do seu texto, pensando em termos de coerência, coesão, contexto de produção, adequação temática, organização textual, observando a situação comunicativa, as características do gênero textual em questão, a clareza das ideias, etc., mantendo-se ligados às questões de superfície, aos aspectos gramaticais, ortográficos e de pontuação. Comprovamos que existe uma grande resistência por parte dos alunos com relação à revisão e reescrita, e eles desconhecem a importância de tais atividades.

Esses dados no levam a acreditar que a revisão e a reescrita não estejam sendo trabalhadas na escola como deveriam ser. Conjecturamos, a partir dos dados encontrados nas respostas dos estudantes, que o texto do aluno é corrigido superficialmente e devolvido, encerrando-se aí o trabalho de produção textual. Não percebemos uma interlocução entre o professor e o aluno sobre o texto produzido. Reescrever parece uma atividade pouco valorizada, compreendida, exercitada.

Embora haja muitos estudos sobre produção textual na escola assim como pesquisas sobre a importância da reescrita, nos parece que etapas fundamentais para o desenvolvimento da produção textual como esta ainda não são didaticamente conduzidas em sala de aula como deveriam ser, de forma a levar o aluno a ver a reescrita como essencial para que sua produção alcance o resultado desejado, de forma que o leitor compreenda a ideia exposta, o que, com certeza, vai muito além de ter um texto gramaticalmente e ortograficamente correto. 


\section{REFERÊNCIAS}

ANTUNES, I. Aula de Português: encontro e interação. São Paulo: Parábola, 2003.

BAKTIN, M. Estética da criação verbal. 6. ed. São Paulo: Martins Fontes, 2011.

BRASIL. Parâmetros Curriculares Nacionais: língua portuguesa: terceiro e quarto ciclos. Brasília: MEC/SEF, 1998.

DOLZ, J.; NOVERRAZ, M.; SCHNEUWLY, B. Sequências didáticas para o oral e a escrita: apresentação de um procedimento. In: SCHNEUWLY, Bernard e DOLZ, Joaquim et al. Gêneros orais e escritos naescola. Tradução e organização de Roxane Rojo e Glaís Sales Cordeiro. Campinas: Mercado de Letras, 2004.

FIAD, R. S.; MAYRINK-SABINSON, M. L. T. A escrita como trabalho. In: MARTINS, M. H. (Org.).Questões de linguagem. São Paulo: Contexto, 2015.

GERALDI, J. W. et al. (org.). O texto na sala de aula. 3. ed. São Paulo: Ática, 2011. . Portos de Passagem. 5 ed. São Paulo: Martins Fontes, 2013.

GRILLO, S. V. C. Escrever se aprende reescrevendo:um estudo da interação professor/aluno na revisão de textos. Dissertação (Mestrado em Linguística Aplicada), Unicamp/IEL, Campinas, 1995.

GUSMÃO, M. A. P. A (re)escrita de textos: a prática pedagógica da professora Maria. Vitória da Conquista: Edições UESB, 2015.

JESUS, C. A. Reescrevendo o texto: a higienização da escrita. In: GERALDI, J.W.; CITELLI, B. (Org.) Aprender e ensinar com textos dos alunos. vol. 1. 7ed. São Paulo: Cortez, 2011.

KATO, M. A. No mundo da escrita: uma perspectiva psicolinguística. 7. ed. São Paulo: Ática, 1995.

LEITE, E. G. A reescritura do aluno sob a orientação do professor.Dissertação (Mestrado em Linguística), Universidade Federal da Paraíba, João Pessoa, 2009.

LEITE, E. G.; PEREIRA, R. C. M. Implicações da correção do professor na reescrita do aluno: Desenvolvendo as capacidades de linguagem. In: BAZARIN, M; GONÇALVES, A. V.(Orgs.) Interaşão, gênero e letramento: a reescrita em foco. 2 ed. Campinas, SP. Pontes Editora, 2013. 
MARCUSCHI, Luiz Antonio. Gêneros textuais: definição e funcionalidade. In: Gêneros textuais e ensino.Dionísio, A. P.; Machado, A. R.; Bezerra, M. A.(org.). São Paulo: Parábola, 2010.

MENEGASSI, R. J. Da revisão à reescrita:operações e níveis linguísticos na construção do texto. Tese (Doutorado), Programa de Pós-Graduação em Letras, Universidade Estadual Paulista, Assis-SP, 1998.

- A revisão de textos na formação docente inicial. In: BAZARIN, M; GONÇALVES, A. V.(Orgs.) Interação, gênero e letramento:a reescrita em foco. 2 ed. Campinas, SP. Pontes Editora, 2013.

NASCIMENTO, C. E. Os bilhetes orientadores da reescrita e a aprendizagem do gênero relatório. In: BAZARIN, M; GONÇALVES, A. V.(Orgs.) Interação, gênero e letramento: a reescrita em foco. 2 ed. Campinas: Pontes Editora, 2013.

SCHNEUWLY, Bernard; DOLZ, Joaquim. Gêneros orais e escritos na escola. Tradução e organização de Roxane Rojo e Glaís Sales Cordeiro. Campinas: Mercado de Letras, 2004.

SERAFINI, M. T. Como escrever textos. 12. ed. São Paulo: Globo, 2004. 